\title{
Parasitic Diseases: Opportunities and Challenges in the 21st Century
}

\author{
Daniel G Colley
}

Division of Parasitic Diseases, National Center for Infectious Diseases, Centers for Disease Control and Prevention, Public Health Service, U.S. Department of Health and Human Services, Building 102, MS F-22, Atlanta,

Georgia 30341, USA

The opportunities and challenges for the study and control of parasitic diseases in the 21st century are both exciting and daunting. Based on the contributions from this field over the last part of the 20th century, we should expect new biologic concepts will continue to come from this discipline to enrich the general area of biomedical research. The general nature of such a broad category of infections is difficult to distill, but they often depend on well-orchestrated, complex life cycles and they often involve chronic, relatively well-balanced host/parasite relationships. Such characteristics force biological systems to their limits, and this may be why studies of these diseases have made fundamental contributions to molecular biology, cell biology and immunology. However, if these findings are to continue apace, parasitologists must capitalize on the new findings being generated though genomics, bioinformatics, proteomics, and genetic manipulations of both host and parasite. Furthermore, they must do so based on sound biological insights and the use of hypothesis-driven studies of these complex systems. A major challenge over the next century will be to capitalize on these new findings and translate them into successful, sustainable strategies for control, elimination and eradication of the parasitic diseases that pose major public health threats to the physical and cognitive development and health of so many people worldwide.

Key words: parasitic diseases - research - molecular biology - cell biology - immunology - control

Human parasitic diseases are caused by numerous, widely disparate infectious organisms. Many require transmission by complex vectors. Some involve intermediate hosts. A few can be acutely lethal. Many result in chronic infections that often cause severe morbidity in only a relatively small proportion of those infected. Several are among the most prevalent infections in the world, and severe morbidity in even a low percentage of those infected results in major global burdens of disease. Some occur only sporadically and infrequently. These seemingly all-encompassing characteristics make parasitic diseases some of the most interesting, challenging and important infectious diseases facing scientists, clinicians, and public health officials as we move into the 21 st century. This presentation will address the future of parasitology by first citing examples of the recent progress and contributions from this field, and then by examining some of the scientific and public health promises and challenges that lie before us.

Fax: +1-770-488.7794. E-mail: DColley@cdc.gov

Received 7 August 2000

Accepted 4 September 2000
BASIC SCIENCE CONTRIBUTIONS FROM THE WORLD OF PARASITOLOGY

Parasitology and host/parasite relationships have been fertile ground for basic molecular biology, cell biology, and immunology research over the last part of the 20th Century. The role of basic biomedical research is to discover and understand the fundamental processes of how cells and organisms work. I believe that parasites and parasitic diseases are good systems for fundamental investigations because of their inherent complexity and their apparent necessity to develop unique "outer limit" mechanisms to solve their survival needs. The down-side of this, of course, is also their complexity. Nevertheless, the extreme lengths to which parasites and hosts go to reach arrangements that allow the viability of both can stretch each others' biological systems to an extent that new processes become observable. Sorting out how these things happen is challenging, but the observations are often there. The burden is then on the investigator to determine how to attack the problem with productive experimental approaches and how to grasp the appropriate understanding of what is observed.

\section{MOLECULAR BIOLOGY}

In the world of molecular biology this approach has been best seen in the early and continuing work 
on African trypanosomes, where the molecular mechanisms that provide the basis of antigenic variation (Borst et al. 1998, Donelson et al. 1998), RNA processing by trans-splicing of polycistronic mRNA (Agabian 1990), and post-transcriptional mitochondrial RNA editing (Benne 1994) have been very illuminating. These organisms, which must survive in the hostile environment of the host's blood, totally exposed to the host's immune mechanisms, exhibit fundamental mechanisms that suit their needs (Donelson et al. 1998), and in so doing, provide insight into what molecular genetic tricks can be available to eucaryotic organisms. The additional finding and mechanistic understanding of RNA processing by trans-splicing in nematodes (Nilsen 1997) and other organisms further illustrates the means used by such eucaryotes to accomplish their needs, expanding how we think about molecular machinery and options.

\section{CELL BIOLOGY}

Cell biologists interested in parasites are continually learning that various organisms contain previously unrecognized organelles to allow them to perform in their particular host environments, and that these organelles often accomplish tasks in previously unknown ways. It is now clear that almost all apicomplexans (including Plasmodium, Toxoplasma, Babesia, and Eimeria) contain an endosymbiotic organelle called an "apicoplast" (Roos et al. 1999a). The fact that the apicoplast is essential to these organisms is now clear, as is its algal origin, the sequence of its $35 \mathrm{kB}$ genome, and its existence within a 4 unit membrane. However, its actual essential function is still unclear (Roos et al. 1999a). The apparent lack of an apicoplast in the apicomplexan Cryptosporidium parvum (Zhu et al. 2000) is a medically important enigma, since it may explain why the drugs most often used against other members of this group of parasites are not effective against $C$. parvum. Trichomonads contain a unique organelle called the hydrogenosome, which lacks DNA, cytochromes, or the citric acid cycle, but rather produces ATP using pyruvate as a primary substrate, in conjunction with enzymes typical of anaerobic bacteria (Muller 1993, Johnson et al. 1995). A still different organelle has now been identified in trypanosomatids, Toxoplasma and Plasmodium, that provides a unique method of managing $\mathrm{Ca}++$ ions in a homeostatic status (Marchesini et al. 2000). It is called an acidocalcisome.

In addition to specific, unique organelles that allow parasites to carry out their needed functions, it is also true that many of our early concepts of receptor/ligand interactions stem from studies of host/parasite interactions. Examples of these find- ings would be the use by Plasmodium to use erythrocytic surface components such as Duffy blood group antigens and glycophorin A as specific receptors for their ligands, in gaining entrance into their target cells (Sinis \& Sim 1997).

The intracellular lifestyles of various eucaryotic parasites is highly varied, and can be informative; in regard to basic cell biology and the mechanisms developed and exploited by various organisms (Bogdan \& Rollinghoff 1999). T. gondii lives within its own specialized, intracellular, parasitophorous vacuole, never fusing with endosomes or lysosomes, thus totally avoiding major defense mechanisms of the host cells (Lingelbach \& Joiner 1998, Mordue et al. 1999). $P$. falciparum also exists within its own parasitophorus vacuole. The mechanisms by which organisms obtain nutrients and excrete wastes and export other parasite components are intimately involved with the architecture and function of their parasitophorous vacuoles (Foley \& Tilley 1998, Lingelbach \& Joiner 1998). Meanwhile, Leishmania spp. develop within fully developed acidic phagolysosomes that are intended to destroy the invaders (Alexander et al. 1999), albeit it seems that their lipophosphoglycan, GP63, as expressed on promastigotes, initially inhibits phagolysosomal fusion, perhaps allowing the organism to get a head start and begin its transformation into amastigotes (Desjardins \& Descoteaux 1997). Trypanosoma cruzi at first actually penetrates its host cells in part using cell lysosomal fusion (Tardieux et al. 1992), but in one to two hours after cell invasion the vacuoles are disrupted and the parasites escape into the cytoplasm of the cell, where they replicate, unhindered by intracellular defense mechanisms (Nogueira \& Cohn 1976). Several protozoan parasites, including Plasmodium spp. are now known to develop extensive tubular vesicular membranes with their host cell as a means of transport beyond the parasite, through the host cell to the external environment (Lauer et al. 1997, Wiser et al. 1997, Foley \& Tilley 1998).

In a truly outstanding feat, the nematode Trichinella spiralis is also an intracellular pathogen. This worm actually enters a striated skeletal muscle cell, which serve as its host cell in its tissue phase, and commandeers the cell machinery to an extent that the cell becomes what is known as a "nurse cell" (Despommier 1993). Nurse cells develop and maintain T. spiralis larvae throughout years and years in the muscle. The intracellular worm/nurse cell complex directs such cellular functions as the restructuring of blood vessels and deposition of specific forms of collagen as protective shields around themselves (Capo et al. 1998). 


\section{IMMUNOLOGY}

Immunoparasitology has provided important insights into fundamental cellular and humoral immune mechanisms that contribute to all of immunology. A wide variety of immune evasion mechanisms are used by various parasites. Perhaps the best known has already been mentioned, the antigenic variation expressed by African trypanosomes (Borst et al. 1998, Donelson et al. 1998). However, there are many other clever strategies used by parasites. Tissue-dwelling cestodes display a co-existence trick that involves the control of host complement activation. The hydatid cysts of Echinococcus granulosus and Taenia solium in its cysticercosis metacestode form are very effective at actively avoiding complement activation via, among other mechanisms, sequestration of factor $\mathrm{H}$ and elaboration of paramyosin, which inhibits C1q (White et al. 1997, Ferreira et al. 2000). Adult schistosomes reduce their surface antigenicity, in part by acquiring antigenic components from their hosts (Pearce \& Sher 1987), and T. cruzi appears to confuse effective host immune responses through the use of multiple variant $\mathrm{T}$ cell epitopes (Millar et al. 1999). It is clear that various intracellular protozoans distinctly alter the capabilities of host macrophages (Reiner 1994, LaFlamme et al. 1997, Kane \& Mosser 2000) and dendritic cells (Urban et al. 1999, Van Overtvelt et al. 1999), altering their effectiveness as antigenprocessing cells. This frontal assault on the fundamental immune presentation mechanisms of the host can considerably alter how immune responses are mounted. Once more fully understood, this knowledge might be useful in directing altered immune capabilities.

The best known contribution of immunoparasitology to the world of fundamental immunology is its contribution to the establishment of the Th1/ Th2 paradigm (Scott et al. 1989). This was initially worked out in regard to leishmanial infection where resistance is dependent on the development of CD4+ Th1 cells which respond appropriately, leading to the induction of effective intracellular killing of the organisms by activated macrophages (Liew et al. 1999). Through the elaboration of these findings, and the reverse side of the story involving differential Th2 stimulation by various helminths (such as schistosomes and filarids) (Scott et al. 1989, Finkelman et al. 1991, Maizels et al. 2000) immunoparasitology has lead the way into an understanding of differential CD4 responsiveness and the functional cytokine profiles that are associated with it. These insights will prove valuable in trying to further understand various autoimmune diseases, asthma and atopic allergies, and various immune diseases involving granuloma formation and its regulation. The delicate balance of immunoregulatory responses and maternal/perinatal immune influences can also be dissected in these chronic model systems, such as in schistosomiasis and Chagas' disease, where perinatal idiotypic and anti-idiotypic interactions are seen to be associated with subsequent levels of morbidity (Colley 1990, Montesano et al. 1999).

\section{ANTI-PARASITIC DRUG DEVELOPMENT}

Coupled with the discussion of potential unique drug targets in protozoan organelles described above, it also bears mentioning that work on parasite cysteine proteases and their inhibitors is a major contributor to the very active field of protease inhibitors as effective antimicrobial and antitumor agents (McKerrow et al. 1999). Using inhibitor design models that are based on the structure of parasite cysteine proteases, it has been feasible to develop interesting leads for drugs against a spectrum of protozoans, including T. cruzi, $P$. falciparum, Leishmania major and T. brucei (McKerrow et al. 1999). Examples of non-parasite targets of protease inhibitors include angiotensin-converting enzyme for the treatment of hypertension and proteases involved in the proliferation of the human immunodeficiency virus. New findings in the area of parasite cysteine protease inhibitors may lead to a fuller understanding of these agents and how they can be used effectively.

These few examples indicate what parasitology can contribute to general biomedical research when thought of, used, and appropriately dissected as model systems. As mentioned above, because these systems often push biological mechanisms to their limits, they can be expected to continue to yield future insights into fundamental areas of molecular biology, cell biology, and immunology.

\section{BASIC SCIENCE NEEDS IN PARASITOLOGY}

If parasitology is to continue to provide new, exciting insights into the world of biological mechanisms and biomedical research, its investigators must take full advantage of the newest tools and approaches available, and work hard to adapt them to their needs and questions. As investigators have striven to do so with certain protozoans over the last 15-20 years, they must now forge ahead to develop models that include a wider spectrum of parasites.

The genome sequencing programs under way with various protozoans and helminths are a clear indication of the intent of investigators in this field to move forward. Because of its obvious public health importance, work on the $P$. falciparum genome is leading the way (Gardner et al. 1998, Su 
et al. 1999, Lai et al. 1999), but following closely and using several sequencing approaches, bioinformatics and functional genomics are $T$. gondii (Ajioka et al. 1998, Manger et al. 1998, Roos et al. 1999b), L. major (Ivens \& Blackwell 1999) and the trypanosomes (Donelson 1996, Degrave et al. 1997, Blackwell \& Melville 1999). The initial push will certainly be to use these tools for drug target and vaccine target discovery, but the yield will also be in areas of basic understanding of the genetics, biochemistry, cell biology, and even epidemiology of the organisms. Helminth genomics has struggled to develop apace, and now, with the completion of the Caenorhabditis elegans genome sequencing (The C. elegans Sequencing Consortium 1998), an emphasis in parasitic nematode genomics (Tetteh et al. 1999, Williams et al. 2000) is greatly needed. Trematode genomics is beginning to take shape with recent renewed interest in Schistosoma mansoni (Le Paslier et al. 2000), but work in cestode genetics is still at the analysis stage (Zhang et al. 1999).

The incipient development of DNA microarrays to detect gene expression of $P$. falciparum (Hayward et al. 2000) is a welcome arrival on the current scene. These technologies will clearly contribute greatly to the ability to detect expression under multiple conditions of interest. Initially these are likely to yield profiling (or "fishing") expeditions, but those will be useful in laying the ground work, and hypothesis-driven studies will soon follow as the techniques are further developed and made more readily available to a larger number of investigators.

The vast development of immune cell markers, transgenic and knockout hosts, recombinant immune components, such as cytokines, chemokines and their receptors, and monoclonal reagents have made experimental and human immune studies much more wondrous and amazing. Much of this work is still in the dissecting phase, where the amount of information generated is far ahead of our true understanding. Yet even so, important insights have been made. The future will rest on the effective use of genomics, reverse genetic analysis, proteomics and bioinformatics. Using these exciting tools in the proper host/parasite/vector context should yield new and useful understandings, leading to such tools as vaccines, drugs, and genetic manipulations that will substantially increase our ability to treat, control, and prevent many of these diseases.

PARASITIC Diseases THAT POSE PUBLIC HEALTH THREATS: WHERE ARE WE, AND WHAT IS TO BE DONE?

The list of parasitic diseases that are known to pose serious public health problems often depends on where one is on the globe and can, of course, be debated by scientists and public health officials. However, in general, which ever candidates make one's final list, the picture is long and sobering (Table I). Yet major advances against these scourges have been made, are currently being made, and will continue to be made to an even greater degree in the 21 st century. How has this occurred thus far, and how will it progress in the future? The path is not a simple one. It is a long and winding road that begins with scientific discovery and understanding, leads to tool development and comprehension of how best to use these tools, and progresses on to policy and decision making, implementation and management. Throughout this entire process the need for scientific research continues, but the nature of that research effort changes and refocuses as the process moves ahead.

So where are we now in the world of curtailing morbidity and mortality caused by parasitic diseases? First, I should define what I mean by the various levels of limiting parasitic diseases or their consequences. My definitions are very close to those agreed to at the Dahlem Conference (Dowdle \& Hopkins 1998), and reported again by Dowdle (1998). The entry level of such programs is control. The term control implies that through deliberate efforts we can decrease transmission or severity of a given infection, and that the implementation of this ability will need to be an ongoing

TABLE I

Major parasitic disease public health threats

\begin{tabular}{ll}
\hline Major killers & Impair development or quality of life \\
\hline Malaria & Lymphatic filariasis \\
Chagas disease & Schistosomiasis \\
African trypanosomes & Soil-transmitted helminths \\
Visceral leishmaniasis & Onchocerciasis \\
& Cysticercosis \\
& Waterborne and foodborne protozoans \\
& Dracunculiasis \\
& Cutaneous leishmaniasis \\
\hline
\end{tabular}


activity for the foreseeable future. Examples of diseases that are currently thought to be, with sufficient effort, controllable are malaria and the soiltransmitted helminths. Elimination of a disease is the next step past control. This means that appropriate implementation of the available tools can reduce the incidence of the disease in people (not necessarily other host species) to zero. Some have also inserted in this definition the phrase "as a public health problem". This then might apply to a zoonosis that no longer threatens people, but continues to be transmitted among other potential reservoir hosts. Elimination of an infection (either complete or as a public health problem) is defined as removing the threat of infection to a level at which it is no longer transmitted, but from which it could return. In the case of elimination, surveillance for a re-emergence of the disease is still needed, but further efforts at elimination are not warranted unless surveillance detects the occurrence of cases. The next level of such activities is eradication. Full eradication is the permanent reduction to zero of the global incidence of a disease. Once accomplished, neither further prevention nor surveillance are needed. In theory, an infection could be eradicated and yet the organism that causes the disease could be housed in a secure condition. To carry eradication to its full and logical conclusion, the total expungement of the organism responsible would require a further step, that is the extinction of that species. In addition to these strict definitions of control, elimination and eradication, it is possible to think of them as being applied to a given geographic area. Thus, elimination of polio has been achieved in the Americas, yet imported cases do still occur, so continued immunization must continue. When polio is eradicated from the world, as smallpox has been, there will no longer be any need to be immunized against polio, or to maintain surveillance for cases of polio. Similarly, India, once the country with a high number of cases of dracunculiasis (Guinea worm disease), has now been certified by the International Commission for the Certification of the Eradication of Dracunculiasis as having eradicated this debilitating infection (Holden 2000).

How does the decision get made to launch a control, elimination, or eradication program (Dowdle \& Hopkins 1998)? Table II outlines some aspects of the problem that must be considered to be able to make such a momentous decision. The combination of appropriate tools, and the ability to use them in an effective and cost-effective manner must be coupled solidly to both the availability of sustained funds for the job, and the will to do the job. It bears remembering that the cost of a bad decision, that is, one based on an inappropri- ate strategy or mis-reading of public support, is very high, and can result in major adverse consequences for other fledgling or future efforts (Cochi et al. 1998, Henderson 1998).

\section{TABLE II}

Decision making: eradication/elimination/control

Ability of available tools vs need for further extensive research

Epidemiologic vulnerability: ability to implement available tools in a cost-effective manner

Availability of sustained funding (public and private)

Political will, as based on:

burden of disease

perception and promotion of outcome

impact on over all health services sector

impact on over all development

personal leadership involvement

I think it is useful, before I discuss the future of such programs, to remember that several control, elimination and even "geographically defined eradication" campaigns against parasitic diseases have been highly successful over the last century. For example, through both dedicated campaigns and eventual rising standards of living, both the United States and Japan have very successfully eliminated geohelminths and malaria as major public health problems. Even more dramatically, again through highly organized campaigns, Japan "geographically eradicated" both filariasis and schistosomiasis. A review of the history of these events clearly demonstrates that they were extraordinary accomplishments, and were not just the result of an increasingly higher standard of living (Sasa 1976, Tanaka \& Tsuji 1997). The certification of eradication of dracunculiasis from Pakistan and now India are major milestones in the war against this debilitating disease, and goes along with the dramatic (>97\%) decrease in the global prevalence of Guinea worm disease since the eradication program began in the 80's (Hopkins et al. 1997). Another extraordinary achievement in the realm of elimination of a terrible disease is proceeding in Brazil, Argentina, Uruguay, Paraguay, and Chile. It is called the Southern Cone Initiative against Chagas disease (Schofield \& Dias 1999). This outstandingly successful effort has almost totally eliminated domiciliary transmission of Chagas disease to humans in many parts of the region. It is a remarkable tribute to those involved, the countries involved, the Pan American Health Organization, and the World Health Organization. Similar campaigns in the Andean and Central American regions have begun, but face some challenges that again 
point out the parallel need for continued research efforts with all implementation programs.

So where are we at this time in regard to such programs against parasitic diseases? Table III lists those major programs that are now ongoing at one level or another, as well as examples of proposed target diseases for future independent or integrated campaigns. The discussion of the independence vs integration of control, elimination, or eradication programs is beyond the scope of this presentation, but it is one that will need to be examined effectively in the future.

\section{FINAL DISCUSSION}

Now I enter into the wild world of forecasting, prediction, and gambling. What will the future look like for those who investigate parasitic diseases and those who seek to deliver us from their devastation? I predict that the future will be very busy. Based on the ongoing successes in both the basic science and field implementation areas of parasitic diseases during the last $15-25$ years, I fully believe that the next century will see major advances in our understanding of both the biologic and behavioral science aspects of these diseases, and that this will be translated into successes in greatly decreasing their impact on human health around the globe. With these advances will come progress in human and societal development. The most prominent challenges, or rather opportunities, that I see during the next 25-50 years are listed in Table IV. The potential in vaccine development and delivery (i.e., progress in adjuvants based on better basic immunologic understandings), coupled with further recognition of the role of host genetics, will greatly change what is in the tool box for preventing these infections. The promise of genetic manipulations of vectors, always an appropriate tar- get for attacking transmission, is outstanding. Genomic information, translated into functional understandings of pathways and targets, will surely assist greatly in the war against drug resistance and provide us with the means to design multi-focal drugs to delay such resistance. Regarding host genetics, some of the pioneering works indicating that infectious diseases have "helped" shape human evolution have been based on malaria and the genes for sickle cell anemia and HLA antigens (Hill 1999). It is not yet clear how to turn these fascinating findings into interventions, but the scientific avenues that will open up during the 21 st century will certainly hold many new opportunities, and genetic manipulations of hosts may be among them.

The societal challenges (Table IV) are a bit more daunting to some of us, but here again research into the behavioral and societal aspects of these diseases will greatly assist in the implementation of effective measures against them. Also, another major shift in perspecitve in the last few years has been the recognition by agencies and governments that these infections not only result from poverty and poor standards of living, but, in fact, are major contributors to poverty. This fundamental shift in perspective leads to the promotion of economic and social development by attacking these major public health problems. This promises to be a major, driving theme of much of the work on parasitic diseases in the future.

So, sitting on the doorstep of the 21 st century, we see that much has changed in the last 25 years. The first is the greatly increased understanding of the basic science of these organisms. The second is the translation of that understanding into tools appropriate to the task (new drugs, new diagnostics, the continued promise of new vaccines and

TABLE III

Current, initiated, planned and possible parasitic disease eradication, elimination or control programs

\begin{tabular}{ll}
\hline CURRENT & Eradication \\
Dracunculiasis & Control \\
Onchocerciasis & $\begin{array}{l}\text { Eradication/elimination as a public health problem } \\
\text { Elimination/eradication (geographically) }\end{array}$ \\
Chagas disease & \\
Lymphatic filariasis & Control; roll back malaria \\
INITIATED & Control; school-based drug treatment \\
Malaria & \\
Soil-transmitted helminths & Control; school-based drug treatment \\
PLANNED & \\
Schistosomiasis & Eradication \\
POSSIBLE & Elimination \\
Taeniasis and cysticercosis & Control \\
Echinococcosis & Control/elimination (geographically) \\
African trypanosomiasis & \\
Visceral leishmaniasis &
\end{tabular}


TABLE IV

21 st century needs in parasitology: challenges and opportunities of the future

\section{INPUT NEEDS}

Parasite, host and vector genome sequencing

Reverse genetic analysis

Proteomics

Parasite, host and vector bioinformatics

Parasite, host and vector DNA microarrays

\section{SCIENTIFIC CHALLENGES}

Vaccine, adjuvant and delivery systems development Vector manipulation and delivery systems

Drug resistance, drug targets, drug development

Host genetic contribution (manipulation?)

\section{SOCIETAL CHALLENGES}

Universal sanitation and public health

Adequate housing

Available health care

Sustained interest and funding (public and private commitment)

vector manipulations). The third is the ability to analyze the public health impact of these diseases. The fourth is a recent influx of major new sources of funding (The Bill and Melinda Gates Foundation, The Turner Foundation, Rotary International, private industry, The Wellcome Trust, and many others). The fifth is the perception of health as a cornerstone of development, and the political will that is generated by that understanding.

Human parasitic diseases caused by protozoans and helminths include a wide variety of infectious organisms, a broad spectrum of disease processes, and some of the most fascinating scientific and important public health challenges that we will face in the 21st century. Many of these diseases represent very well adapted host/parasite/vector relationships that imply a degree of co-evolution of these "partners in disease" that stretches the imagination. This is often exemplified by chronic infections that, in a high percentage of hosts, cause little morbidity, and life-cycles that are exquisitely timed and organized for optimal, but regulated, transmission of the pathogen. A few of these diseases are more fulminant, and some clearly lead to more disease in recently infected populations of hosts than in long-standing situations of mediumto-high prevalence. Work with these parasites and their hosts and vectors spans the gamut from very basic scientific research, to extremely practical implementation of eradication programs. It is, however, critical to remember that a sound scientific understanding of the organism, the vector and the host, and how they interact biologically, spa- tially, and temporally, is always the foundation upon which effective control, elimination, or eradication programs are based. Until the proper understanding of the situation is in hand, and the appropriate tools are assembled, sheer determination is simply usually not enough to effectively dominate these well-established and spreading diseases. However, when science and public health progress together and join forces, creating a critical mass, true progress can definitely be made. Here, at the beginning of the 21 st century, we have good reasons to be highly optimistic regarding future efforts to make strong progress against some of the oldest and most widespread scourges of mankind. Such progress will undoubtably need to be based on the aggressive pursuit of a better understanding of the organisms, vectors, and hosts. But that alone will not be enough. It is the responsibility of all involved to forge active links between those making these new findings and those seeking to implement the appropriate resultant principles and methodologies in the public health arena. We need to continue to press forward to create the atmosphere that will allow this critical bridge between research and control to flourish, so that all parties: the investigators, the clinicians, the public health officials, patients, and the public, benefit to the greatest extent possible.

\section{REFERENCES}

Agabian N 1990. Trans-splicing of nuclear pre-mRNAs. Cell 61: 1157-1160.

Ajioka JW, Boothroyd JC, Brunk BP, Hehl A, Hillier L, Manger ID, Marra M, Overton GC, Roos DS, Wan K-L, Waterston R, Sibley LD 1998. Gene discovery by EST sequencing in Toxoplasma gondii reveals sequences restricted to the apicomplexa. $\mathrm{Ge}$ nome Res 8: 18-28.

Alexander J, Satoskar AR, Russell DG 1999. Leishmania species: models of intracellular parasitism. J Cell Sci 112: 2993-3002.

Benne R 1994. RNA editing: how a message is changed. Curr Opin Genet Dev 6: 221-231.

Blackwell JM, Melville SE 1999. Status of protozoan genome analysis: trypanosomatids. Parasitology 118 Suppl.: S11-14.

Bogdan C, Rollinghoff M 1999. How do protozoan parasites survive inside macrophages? Parasitol Today 15: 22-28.

Borst P, Bitter W, Blundell PA, Chaves I, Cross M, Gerrits H, van Leeuwen F, McCulloch R, Taylor M, Rudenko G 1998. Control of VSG gene expression sites in Trypanosoma brucei. Mol Bichem Parasitol 91: 67-76.

Capo VA, Despommier DD, Polvere RI 1998. Trichinella spiralis: vascular endothelial growth factor is up-regulated within the nurse cell during the early phase of its formation. J Parasitol 84: 209-214.

Cochi SL, de Quadros CA, Dittmann S, Foster SO, Glavez Tan JZ, Grant FC, Olive J-M, Pigman HA, 
Taylor CE, Wang K 1998. Group Report: What are the societal and political criteria for disease eradication? In WR Dowdle, DR Hopkins (eds), The Eradication of Infectious Diseases, John Wiley \& Sons Ltd, Chichester, p. 157-175.

Colley DG 1990. Occurrence, roles and uses of idiotypes and anti-idiotypes in parasitic diseases. In J Cerny, J Hiernaux (eds), Idiotypic Network and Diseases, ASM Press, Washington p. 71-105.

Degrave W, de Miranda AB, Amorim A, Brandão A, Aslett M, Vandeyar M 1997. TcruziDB, an integrated database, and the WWW information server for the Trypanosoma cruzi genome project. Mem Inst Oswaldo Cruz 92: 805-809.

Desjardins M, Descoteaux A 1997. Inhibition of phagolysosomal biogenesis by the Leishmania lipophosphoglycan. J Exp Med 185: 2061-2068.

Despommier DD 1993. Trichinella spiralis and the concept of niche. J Parasitol 79: 472-482.

Donelson JE 1996. Genome research and evolution in trypanosomes. Curr Opin Genet Dev 6: 699-703.

Donelson JE, Hill KL, El-Sayed NM 1998. Multiple mechanisms of immune evasion by African trypanosomes. Mol Biochem Parasitol 91: 51-66.

Dowdle WR 1998. The principles of disease elimination and eradication. Bull WHO 76 Suppl. 2: 22-25.

Dowdle WR, Hopkins DR 1998. The Eradication of Infectious Diseases, John Wiley \& Sons Ltd, Chichester, 218 pp.

Ferreira AM, Irgoín F, Breijo M, Sim RB, Díaz A 2000. How Echinococcus granulosus deals with complement. Parasitol Today 16: 168-172.

Finkelman FD, Pearce EJ, Urban Jr JR, Sher A 1991. Regulation and biological function of helminth-induced cytokine responses. Immunol Today 12: A62A66.

Foley M, Tilley L 1998. Protein trafficking in malariainfected erythrocytes. Int J Parasitol 28: 1671-1680.

Gardner MJ, Tettelin H, Carucci DJ, Cummings LM, Aravind L, Koonin EV, Shallom S, Mason T, Yu K, Fujii C, Pederson J, Shen K, Jing J, Aston C, Lai Z, Schwartz DC, Pertea M, Salzberg S, Zhou L, Sutton GG, Clayton R, White O, Smith HO, Fraser CM, Hoffman SL 1998. Chromosome 2 sequence of the human malaria parasite Plasmodium falciparum. Science 282: 1126-1132.

Hayward RE, DeRisi JL, Alfadhli S, Kaslow DC, Brown PO, Rathod PK 2000. Shotgun DNA microarrays and stage-specific gene expression in Plasmodium falciparum malaria. Mol Microbiol 35: 6-14.

Henderson DA 1998. Eradication: lessons from the past. Bull WHO 76 Suppl. 2: 17-21.

Hill A 1999. Genetics and genomics of infectious disease susceptibility. Br Med Bull 55: 401-413.

Holden C 2000. Guinea worm banished from India. Science 287: 1917.

Hopkins DR, Ruiz-Tiben E, Ruebush TK 1997. Dracuculiasis eradication: almost a reality. Am J Trop Med Hyg 57: 252-259.

Ivens AC, Blackwell JM 1999. The Leishmania genome comes of age. Parasitol Today 15: 225-231.

Johnson PJ, Bradley PJ, Lahti CJ 1995. Cell biology of trichomonads: protein targeting to the hydrogenosome. In JC Boothroyd, R Komuniecki (eds), Molecular Approaches to Parasitology. Wiley-Liss, New York, p. 399-411.

Kane MM, Mosser DM 2000. Leishmania parasites and their ploys to disrupt macrophage activation. Curr Opin Hematol 7: 26-31.

La Flamme AC, Kahn SJ, Rudensky AY, Van Voorhis WC 1997. Trypanosoma cruzi-infected macrophages are defective in major histocompatibility complex class II antigen presentation. Eur J Immunol 27: 3085-3094.

Lai Z, Jing J, Aston C, Clarke V, Apodaca J, Dimalanta ET, Carucci DJ, Gardner MJ, Mishra B, Anantharaman TS, Paxia S, Hoffman SL, Venter CJ, Huff EJ, Schwartz DC 1999. A shotgun optical map of the entire Plasmodium falciparum genome. Nat Genet 23: 309-313.

Lauer SA, Rothod PK, Ghori N, Haldar K 1997. A membrane network for nutrient import in red cells infected with the malaria parasite. Science 276: 1122-1125.

Le Paslier MC, Pierce RJ, Merlin F, Hirai H, Wu W, Williams DL, Johnston D, LoVerde PT, Le Paslier D 2000. Construction and characterization of a Schistosoma mansoni bacterial artificial chromosome library. Genomics 65: 87-94.

Liew FY, Xu D, Chan WL 1999. Immune effector mechanism in parasitic infections. Immunol Lett 65: 101-104.

Lingelbach K, Joiner KA 1998. The parasitophorous vacuole membrane surrounding Plasmodium and Toxoplasma: an unusual compartment in infected cells. J Cell Sci 111: 1467-1475.

Maizels RM, Allen JE, Yazdanbakhsh M 2000. Immunology of lymphatic filariasis: current controversies. In TB Nutman, Lymphatic Filariasis, Imperial College Press, London, p. 217-243.

Manger ID, Hehl A, Parmley S, Sibley LD, Marra M, Hillier L, Waterston R, Boothroyd JC 1998. Expressed sequence tag analysis of the bradyzoite stage of Toxoplasma gondii: identification of developmentally regulated genes. Infect Immun 66: 1632-1637.

Marchesini N, Luo S, Rodrigues CO, Moreno SN, Docampo R 2000. Acidocalcisomes and a vacuolar $\mathrm{H}+-$ pyrophosphatase in malaria parasites. Biochem J 347: 243-253.

McKerrow JH, Engel JC, Caffrey CR 1999. Cysteine protease inhibitors as chemotherapy for parasitic infections. Bioorg Med Chem 7: 639-644.

Millar AE, Wleklinski-Lee M, Kahn SJ 1999. The surface protein superfamily of Trypanosoma cruzi stimulates a polarized Th1 response that becomes anergic. J Immunol 162: 6092-6099.

Montesano MA, Colley DG, Eloi-Santos S, Freeman Jr GL, Secor WE 1999. Neonatal idiotypic exposure alters subsequent cytokine, pathology, and survival patterns in experimental Schistosoma mansoni infections. J Exp Med 189: 637-645.

Mordue DG, Hakansson S, Niesman I, Sibley LD 1999. Toxoplasma gondii resides in a vacuole that avoids fusion with host cell endocytic and exocytic vesicular trafficking pathways. Exp Parasitol 92: 87-99. 
Müller M 1993. The hydrogenosome. J Gen Microbiol 139: 2879-2889.

Nilsen TW 1997. Trans-splicing. In AR Krainer, Eucaryotic mRNA Processing, IRL Press, Oxford p. 310-334.

Nogueria N, Cohn ZA 1976. Trypanosoma cruzi: mechanisms of entry and intracellular fate in mammalian cells. J Exp Med 143: 1402-1420.

Pearce E, Sher A 1987. Mechanisms of immune evasion in schistosomiasis. Contrib Microbiol Immunol 8: $219-232$

Reiner NE 1994. Altered cell signaling and mononuclear phagocyte deactivation during intracellular infection. Immunol Today 15: 374-381.

Roos DS, Crawford MJ, Donald RGK, Kissinger JC, Klimczak L, Striepen B 1999a. Origin, targeting, and function of the apicomplexan plastid. Curr Opin Microbiol 2: 426-432.

Roos DS, Darling JA, Reynolds MG, Hager KM, Striepen B, Kissinger JC 1999b. Toxoplasma as a model parasite: apicomplexan biochemistry, cell biology, molecular genetics, genomics... and beyond. In C Tschudi, E Pearce (eds) Biology of Parasitism, Kluwer Academic Publishers, Boston (in press).

Sasa M 1976. Human filariasis.. In A Global Survey of Epidemiology and Control, University Park Press, Baltimore, p. 498-508.

Schofield CJ, Dias JC 1999. The Souther Cone Initiative against Chagas disease. Adv Parasitol 42: 1-27.

Scott P, Pearce E, Cheever AW, Coffman RL, Sher A 1989. Role of cytokines and CD4+ T-cell subsets in the regulation of parasite immunity and disease. Immunol Rev 112: 161-182.

Sinis P, Sim BKL 1997. Cell invasion by the vertebrate stages of Plasmodium. Tren Microbiol 5: 52-8.

Su X, Ferdig MT, Huang Y, Huynh CQ, Liu A, You J, Wootton JC, Wellems TE 1999. A genetic map and recombination parameters of the human malaria parasite Plasmodium falciparum. Science 286: 13511353.

Tanaka H, Tsuji M 1997. From discovery to eradication of schistosomiasis in Japan: 1847-1996. Int $J$ Parasitol 27: 1465-1480.
Tardieux I, Webster P, Ravesloot J, Boron W, Lun JA, Heuser JE, Andrews NW 1992. Lysosome recruitment and fusion are early events required for trypanosome invasion of mammalian cells. Cell 71: 11171130.

Tetteh KKA, Loukas A, Tripp C, Maizels RM 1999. Identification of abundantly expressed novel and conserved genes from the infective larval stage of Toxocara canis by an expressed sequence tag strategy. Infect Immun 67: 4771-4779.

The C. elegans Sequencing Consortium 1998. Genome sequence of the nematode C. elegans: a platform for investigating biology. Science 282: 2012-2018.

Urban BC, Ferguson DJ, Pain A, Willcox N, Plebanski M, Austyn JM, Roberts DJ 1999. Plasmodium falciparum-infected erythrocytes modulate the maturation of dendritic cells. Nature 400: 73-77.

Van Overtvelt L, Vanderheyde N, Verhasselt V Ismaili J, De Vos L, Goldman M, Willems F, Vray B 1999. Trypanosoma cruzi infects human dendritic cells and prevents their maturation: inhibition of cytokines, HLA-DR, and costimulatory molecules. Infect Immun 67: 4033-4040.

White AC Jr, Robinson P, Kuhn R 1997. Taenia solium cysticercosis: host-parasite interactions and the immune response. Chem Immunol 66: 209-230.

Williams SA, Lizote-Waniewski MR, Foster J, Guiliano D, Daub J, Scott AL, Slatko B, Blaxter ML 2000. The filarial genome project: analysis of the nuclear, mitochondrial and endosymbiont genomes of Brugia malayi. Int J Parasitol 30: 411-419.

Wiser MF, Lanners HN, Bafford RA, Favaloro JM 1997. A novel alternate secretory pathway for the export of Plasmodium proteins into the host erythrocyte. Proc Natl Acad Sci USA 94: 9108-9113.

Zhang L, Gasser RB, Zhu X, McManus DP 1999. Screening for different genotypes of Echinococcus granulosus within China and Argentina by singlestrand conformation polymorphism (SSCP) analysis. Trans $R$ Soc Trop Med Hyg 93: 329-334.

Zhu G, Marchewka MJ, Keithly JS 2000. Cryptosporidium parvum appears to lack a plastid genome. Microbiology 146: 315-321. 